\title{
Global stability analysis of structures and actions to control their effects
}

\section{Análise da estabilidade global das estruturas e ações de controle dos seus efeitos}

F. C. FREITAS a

felipecf@ymail.com

L. A. R. LUCHI lorenzo.luchi@terra.com.br

W. G. FERREIRA a walnorio@gmail.com

\begin{abstract}
In this moment in which civil engineering is undergoing a phase where structural projects have been developed with structural systems composed of different and complex elements, some methods and criteria are used for the purpose of evaluating important aspects with regard to global and local stability. Among them, it is necessary to mention the parameters of instability $a$ and $y z$. In this sense, this work has the objective to present the basic concepts of the instability parameters $\alpha$ and $y z$ in accordance with what is clearly defined in the Brazilian standard ABNT NBR 6118; to present the results of simulations of models in the Brazilian structural software TQS varying the stress of compression in the columns in order to relate these values with the stability parameters.
\end{abstract}

Keywords: global stability, gama-z, structural analysis.

\section{Resumo}

Nesse momento em que a Engenharia civil vem passando por uma fase onde os projetos estruturais têm sido elaborados com sistemas estruturais compostos por elementos diferenciados e complexos, alguns critérios e métodos são utilizados com a finalidade de avaliar aspectos importantes no que diz respeito à estabilidade global e local. Entre eles, faz-se necessário citar os parâmetros de instabilidade $\alpha$ e Gama-z. Nesse sentido, este artigo tem o objetivo de apresentar os conceitos básicos dos parâmetros de instabilidade $\alpha$ e Gama-z de acordo com o que é claramente definido na norma brasileira ABNT NBR 6118; apresentar os resultados de simulações de modelos no software estrutural Brasileiro TQS variando a tensão de compressão nos pilares com a finalidade de relacionar estes valores com os parâmetros de estabilidade.

Palavras-chave: estabilidade global, gama-z, análise estrutural. 


\section{Introduction}

The analysis of global stability of structures has become very important nowadays. Civil Engineering, as well as other branches of Engineering, has experienced major advances in their fields. This can be noticed by the total amount built or about to be built by the different companies who operate in construction and design. Not only by the significant number of services, this increasing request of Civil Engineering also becomes cause and incentive for the development of new technical production methods aimed at better results.

Major projects are launched to supply the demand, which comes day after day, whether in residential, commercial or industrial construction. Behind this demand, technical production brings an increase for goods and the requirement for the excellence.

Best practices in design and development projects have been considered in the viability procedures of the projects.

One of the advances is evidenced by the improvement design procedures. Factors previously considered only in special buildings (tall buildings or engineering structures), such as the second order effects and global and local stability of the structures, now become necessary in the evaluation in more joint ventures.

These advances are used by most of the current versions of software to simulate with greater precision the effects to which the structure is subjected in different situations.

The Brazilian regulatory standard "NBR 6118:2014 - Concrete Structures Project - Procedure" establishes, in item 15.5, guidelines for dismissal of the global second-order efforts. To analyze stability, the standard uses two parameters to estimate the secondorder efforts: $\alpha$ (alfa) and $\gamma_{Z}$ (Gama-Z).

The parameter $\alpha$, the simpler of the two, is used to evaluate the global stability in the structure, but is not able to estimate the second-order efforts. This parameter allows classifying a structure as fixed or mobile nodes. Parameter $\gamma_{Z}$, on the other hand, by means of its formulation, allows estimation of the second-order efforts. In this context, this paper is presented, aiming to discuss the main concepts involved in the study of global stability of structures, making use of the stability parameters $\alpha$ and $\gamma_{Z}$.

\section{Brief history of stability parameters: the beginning}

The study on the parameters of stability was started in 1967 by Hurbert Beck and Gert König (1967, cited by Vasconcelos, 1991) after presentation of a doctoral dissertation Germany. This study analyzed the structure of a building with many floors, which were considered the columns braced by rigid walls with a slim structure. Studies led to a complicated solution of the differential equation with variable coefficients, but after a mathematical simplification, the equation was reduced to Bessel functions. Based on the solution of this equation, a parameter called "stability coefficient a" was proposed.

This coefficient was able to provide information of what is the displacement and definitions about fixed and mobile nodes of the structure under analysis. By simplifying displacement calculations of the structure, it states that fixed node structures would be those in which the addition of internal forces (existing moments) was less than $10 \%$ of the internal forces already present. For these cases, the value of the coefficient $\alpha$ would be below 0.6 .

\subsection{Differential equation}

Starting from the differential equation of a straight bar of length $\mathrm{L}$, with constant section and made of a linear elastic material, subject to an axial load $\mathrm{P}$ at the ends, one has:

$$
\frac{d^{2} y}{d x^{2}}+a^{2} \cdot y=0
$$

where $y(x)$ represents the displacement curve of the bar in the transverse direction and $\mathrm{EJ}$ the flexural rigidity. From the equation of the straight bar, it follows that:

$$
a_{c r}^{2}=\frac{P_{c r} \cdot L^{2}}{E J}
$$

where $\mathrm{a}_{\mathrm{cr}}$ is treated such as a stability coefficient and its value is related to the conditions of support from the bar ends. The value of $\mathrm{a}_{\mathrm{cr}}$ is low when the bar is embedded and high when the bar is biarticulated or mono crimped.

\subsection{The differential equation according Beck e König}

The equation proposed by Beck and König (1967, cited by Vasconcelos, 1991) at the time of their studies, was:

$$
y^{\prime \prime \prime \prime}(\xi)+\alpha^{2} \cdot[y(\xi) \cdot(\xi)]^{\prime}=\frac{w \cdot L^{4}}{E J}
$$

when:

$$
\xi=x / L
$$

In this equation, $w$ is the horizontal distributed load across the height $L$ of the building.

After some mathematical operations, the equation of the value of $\alpha$ found by Beck and König was:

$$
\alpha_{c r}^{2}=(p+v)_{c r} \cdot \frac{L^{3}}{E J}
$$

where $p$ is the distributed load to which the bracing structure is subjected and $v$ is the distributed load at the braced structure. In table 1 the limit values found by Beck and König according with the number of floors are shown.

These results were obtained considering that the bracing structure of the building could be replaced by a structure composed of only 


\begin{tabular}{|c|c|c|}
\hline \multicolumn{3}{|c|}{$\begin{array}{l}\text { Table } 1 \text { - Value of } \alpha_{c r} \text { found } \\
\text { by Beck and König }\end{array}$} \\
\hline$\alpha_{\mathrm{cr}}$ & $\begin{array}{l}\text { n (number } \\
\text { of floors) }\end{array}$ & Restriction \\
\hline 2.80 & $n \geq 4$ & - \\
\hline 0.60 & $n \geq 4$ & $\Delta \mathrm{M}_{\text {adic }} \leq 0.10 \cdot \mathrm{M}_{1 \text { aordem,exist }}$ \\
\hline 0.50 & $n=3$ & - \\
\hline 0.40 & $n=2$ & - \\
\hline 0.30 & $\mathrm{n}=1$ & - \\
\hline \multicolumn{3}{|c|}{ Source: Origem dos Parâmetros de Instabilidade $\alpha_{c r}$ e $\gamma_{2}$ (Vasconcelos, 1991) } \\
\hline
\end{tabular}

a single column whose geometric characteristics were equivalent to the original. Thereby, it was decided that the sum of the stiffness of the bracing structure was equal to the rigidity of a single column. To calculate the equivalent rigidity in cases of bracing columns, the horizontal force acting on the spatial frame should be applied, in order to determine the value of the deformation with the horizontal loads. This deformation must be the same as the one obtained from the equivalent column subject to the same horizontal loads. Once calculated the $\alpha$ value, it must be verified to make sure it does not exceed the limit value. In affirmative case, modify the dimensions of the structural elements in order to get below the limit values.

Studies of parameters for stability analysis were continued by other authors with interest in the subject (CEB e ABNT). In 1978, the CEB started using the values $\alpha_{\text {lim }}$ described by Beck \& König, as well as ABNT NBR 9062 (Brazilian code pre-shaped structure). In 1985, Mario Franco (1985) studied again how to obtain the limit values of the stability coefficient for buildings with more than three floors finding values ranging close to 0.6 in structures with wall-like columns, frames and combination frames and wall-like columns. Vasconcelos (1985) found for structures with 1, 2 and 3 pavements values as described in Table 2.

In 1986, Augusto C. Vasconcelos took over studies by Beck \& König, but this time with the advent of the computer, he could assess the same structure previously studied discretized, instead of continuous structure. The results were not different for up to three floors, and from four floors the difference between $\alpha_{c r}$ and $\alpha=2.8$ was decreasing with the increase of the amount of floors. This study resulted in the suggestion of a formula for calculating $\alpha_{\text {cr }}$ according to the number $\mathrm{n}$ of floors. Follows the formula:

\section{Table 2 - Values of $\alpha_{c r}$ in according with the number of floors}

$\begin{array}{cc}\alpha_{\text {cr }} & \mathrm{n} \text { (filoors) } \\ 0.50 & 1 \\ 0.55 & 2 \\ 0.60 & 3\end{array}$

Source: Origem dos Parâmetros de Instabilidade $\alpha_{c r}$ e $\gamma_{2}$ (Vasconcelos, 1991)

$$
\alpha_{c r}=2.8-1.1 \cdot e^{0.22 n}
$$

In 1990, the CEB decides to drop the considerations on the calculation of $\alpha$ stability parameter. In this context, Mario Franco and Augusto C. Vasconcelos (1997, Franco, M. and Vasconcelos, AC, cited Vasconcelos, 1991) introduced the first concept of the amplification coefficient of the moment $\gamma_{Z}$ in the state of Rio de Janeiro, as an auxiliary tool in the study of global stability. Through the P-Delta process, come up to the idea of $\gamma_{Z}$.

When the structure is requested by the loads, it undergoes a displacement altering its original configuration. From this new configuration, new internal forces are created, which in turn generate new displacements. In this continuous process, it is noted that at every step new strains are generated which, compared to the previous results, can be represented by a geometric progression. This progression has the following ratio:

$q=\frac{\Delta M}{M_{1}}$

where:

$$
\Delta M=P \cdot y_{1}
$$

and $y_{1}$ is the eccentricity of first order, and $M_{1}$ it is the first order moment.

Years after the definition of the moment amplification $\gamma_{Z}$, several studies were conducted on this topic. In the year 1993, the TQS creates the Spatial Frame module in which it begins to use the parameters of stability $\alpha$ and $\gamma_{Z}$. Correlations between $\alpha$ and $\gamma_{Z}$ were also formulated as approaches for practical applications. Table 3 has some of the correlations that were presented in articles and studies.

\section{Study of global stability of structures}

\begin{tabular}{|c|c|}
\hline \multicolumn{2}{|c|}{$\begin{array}{c}\text { Table } 3 \text { - Correlations of } \alpha_{c r} \\
\text { and } \gamma_{z}\end{array}$} \\
\hline Authors & Correlations \\
\hline $\begin{array}{l}\text { Prof. Mário Côrrea e } \\
\text { Prof. Marcio Ramalho }\end{array}$ & $\gamma_{z}=1.10-0.33 \alpha+0.50 \alpha^{2}$ \\
\hline $\begin{array}{l}\text { Regina Maria } \\
\text { dos Santos Carmo }\end{array}$ & $\gamma_{z}=0.90+0.52 \alpha-0.62 \alpha^{2}+0.46 \alpha^{3}$ \\
\hline \multicolumn{2}{|c|}{$\begin{array}{l}\text { Source: Origem dos Parâmetros de Instabilidade } \alpha_{c r} \text { e } \gamma_{2} \text { (Vasconcelos, 1991); } \\
\text { "Efeitos de Segunda Ordem em Edifícios Usuais de Concreto Armado", } \\
\text { (Carmo, 1995) }\end{array}$} \\
\hline
\end{tabular}

The study of global stability of the structures has gained a high 


\section{Figure 1 - Relation moment-curvature (extracted by NBR 6118)}

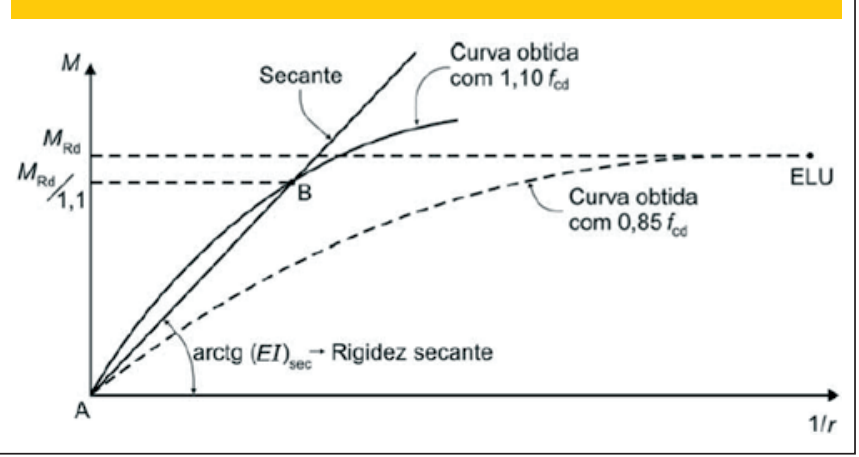

importance position because it has become common to development projects in which buildings have been increasingly high, slender and with features aimed at excellent performance, low consumption of materials, structural systems with speed of execution without giving up the structural safety of the guarantee to the ultimate limit state.

Accordingly, the verification of the global stability can be checked through the global stability parameters, which are described in the standard NBR 6118, in the items 15.5.2 and 15.5.3.

Using these parameters allows us to estimate data on the stability of the structure and estimate the second-order effects in a simplified manner. For this reason, it is necessary to present some concepts related to second-order effects and that should be considered in the project.

\subsection{Related concepts to global stability of structures}

\subsubsection{Physical nonlinearity}

According to NBR 6118, in section 15.3, structural analysis considering the effects of second order shall take into account the effects of physical nonlinearity. The nonlinearity is related to the behavior of the material, which in the case of reinforced concrete can be considered a non-linear material. The effects caused by creep, shrinkage and concrete cracking affect the final value of concrete elastic modulus, hence the physical non-linearity of concrete. For consideration of these effects, the rule establishes the concept of moment-curvature, shown in Figure 1.

According Moncayo (2011), the advantage in using the moment-curvature relationship is due to the fact that is possible to directly obtain the value of rigidity $\mathrm{El}$, which is used in the structural analysis. In the case of the study of global stability, the NBR 6118 states, in section 15.7.3, that the consideration of the approximated nonlinearity takes as stiffness of structural elements the following values:

Slabs: $(\mathrm{EI})_{\mathrm{sec}}=0,3 \mathrm{E}_{\mathrm{ci}} \mathrm{I}_{\mathrm{c}}$

Beams: $(\mathrm{EI})_{\mathrm{sec}}=0,4 \mathrm{E}_{\mathrm{ci}} \mathrm{I}_{\mathrm{c}}$ para $\mathrm{A}_{\mathrm{S}}^{\prime} \neq \mathrm{A}_{\mathrm{s}}$

$(\mathrm{EI})_{\mathrm{sec}}=0,5 \mathrm{E}_{\mathrm{ci}} \mathrm{I}_{\mathrm{c}}$ para $\mathrm{A}_{\mathrm{s}}^{\prime}=\mathrm{A}_{\mathrm{S}}$

Columns: $(\mathrm{EI})_{\mathrm{sec}}=0,8 \mathrm{E}_{\mathrm{ci}} \mathrm{I}$

where:

$I_{c}$ is the moment of inertia of the gross concrete section, including, where applicable, the co-operating tables (T section),
$A_{\mathrm{s}}^{\prime}$ is the compression reinforcement when double armor

$A$ is the tensile armor,

$\mathrm{E}_{\mathrm{si}}^{\mathrm{s}}$ is the initial modulus of elasticity of the concrete, given by $\mathrm{E}_{\mathrm{ci}}^{\mathrm{ci}}=5600 \cdot \sqrt{\mathrm{f}_{\mathrm{ck}}}$;

$\mathrm{f}_{\mathrm{ck}}$ is the characteristic compressive strength of concrete in MPa.

The approximate stiffness values must be used according to the conditions described in paragraph 15.7.3 of NBR 6118.

\subsubsection{Geometric nonlinearity}

The consideration of the effects of geometric nonlinearity is related to changes that may occur in the geometry of the structural elements. Like the physical nonlinearity, it is also determined by analyzing the deformed structure. Specially for high buildings, the consideration of the effects of geometric nonlinearity becomes important because it generates increased internal forces due to vertical loads and horizontal displacements.

For the consideration of geometric nonlinearity it is common to use the $\mathrm{P}-\Delta$ process, where is conducted the study considering the deformed structure.

\subsubsection{Stiffness of structural elements}

The rigidity of the structural elements has a direct influence on the overall stability of a structure. In a conventional structure, consisting of columns, beams and slabs, the main elements that will work to ensure stability are the columns and beams. This fact can be seen taking the NBR 6118 approximate stiffness values for the slabs, which are lower compared to the stiffness of the beams and columns. In fact, the slabs will work in another property giving overall stability study: The hard diaphragm. The slabs are considered as rigid elements in their own plane, aligning the displacements at all points of this plane.

Another important consideration to be made is the consideration of hard cores in the buildings. Normally they are formed by large columns with "C" shape, and located in the stairs and elevators. This type of structure has a high flexural rigidity in the analysis of stability and horizontal displacement parameters, contribute significantly.

\subsection{Global stability parameters}

Following studies on the effects of second-order structures, the NBR 6118 code, in chapter 15 - "Instability and second-order effects", provides guidelines on how to apply test methods and analysis of second-order effects.

For their use, it is considered that it is applied to structures with bars subject to flexion-compression efforts that must disregard the twist. The concepts apply to shells structures, walls and wallbeams. The second order effects are those in which the equilibrium analysis is done using the deformed configuration.

The code adopts that to disregard the second-round effects the increases caused by these should not exceed $10 \%$ in the reactions and the loads of the structure. It should also ensure that the calculated bearing capacity should not be surpassed.

\subsubsection{Stability parameters $(\alpha)$}

The structure classification as the lateral displaceability of the nodes 


\section{Figure 2 - Equivalence of stiffness - analogy with column in balance}
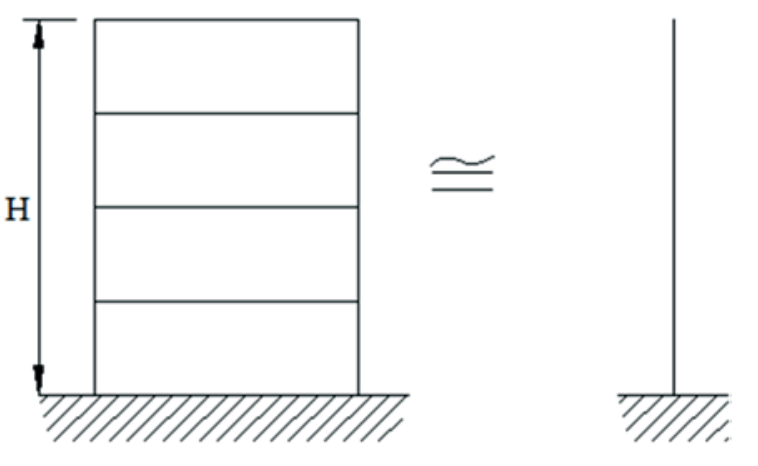

is performed by the Stability parameter $\alpha$. Above a certain limit value, the structure is classified as of mobile nodes, and therefore should be considered second-order analysis. It is emphasized that the parameter is not able to estimate the effects of second order. Assuming initially that the bracing structure may be represented by a single column clamped at the base and free at the top, an equivalent $E_{j k}$ stiffness of the sum of the stiffness of the bracing columns of the structure (figure 2) and being constant over the height $\mathrm{H}$ of the building, we have the following value for the parameter of instability:

$$
\alpha=H \cdot \sqrt{\frac{P_{k}}{E J_{k}}}
$$

In equation $9, P_{k}$ is the sum of all the vertical loads of the structure. It will be a caveat that the amounts to be used are characteristic.

$$
P_{d}=\gamma_{f} \cdot P_{k}=1.4 \cdot P_{k}
$$

$$
(E J)_{d}=0.7 \cdot(E J)_{k}
$$

The index "d" indicates design values.

The condition for the structure to be fixed nodes is that $\alpha<\alpha_{1}$, thereby $\alpha_{1}$ equal to:

$$
\begin{aligned}
& \alpha_{1}=0.2+0.1 \cdot n \text { if } n \leq 3 \text { floors } \\
& \alpha_{1}=0.6 \text { if } n \geq 4 \text { floors }
\end{aligned}
$$

The limit value $\alpha_{1} \leq 0.6$, when used in structures with less than four floors, is generally well applicable to most building structures. However, when the bracing structure is formed exclusively by walllike columns and frames, the value of $\alpha_{1}$ should be changed. The new limit values are described below:

$-\alpha_{1}=0.7$ For bracing with wall-like columns;

- $\alpha_{1}=0.6$ For mixed bracing (wall-like columns + frames);

$-\alpha_{1}=0.5$ For bracing in frames.

The equivalent stiffness of the bracing elements (framed systems and mixed systems) of the structure is calculated by using the lateral characteristic load over the entire height of the building and determining its roof top displacement $\delta$.

Obtained the deformation on top of the building is done with that for a new column equivalent balance, with constant equivalent stiffness, under the action of the same loading, this new column in balance suffer the same displacement at its end cantilevered. Assuming that the load is constant over the entire height of the building, it becomes

$(E I)_{k}=\frac{q_{k} \cdot H^{4}}{8 \cdot \delta}$

where:

$q_{k}$ is the lateral load characteristic;

$H$ is the total height of the building;

$\delta$ is the displacement at the top of the building.

\subsubsection{Coefficient $\gamma_{z}$}

The Brazilian code gives the coefficient $\gamma_{z}$ assessing the presence or absence of second-order global efforts in framed structures with at least four floors.

For the determination of its value, it is necessary to make a first order analysis for each loading case. The formula for $\gamma_{z}$ is:

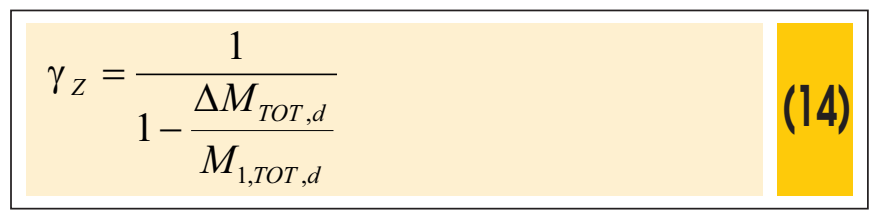

where:

$M_{1, T O T, d}$ is the moment of tipping. It is the sum of the moments of all horizontal forces in the considered combination, with design values, in relation to the base structure.

$\Delta M_{T O T, d}$ is the sum of the multiplication of the vertical forces acting on the structure, in the combination design values considered, for horizontal displacement of the respective points of application. The above values are obtained by first order analysis.

For the structure to be considered as a fixed node structure, the condition is that:

$$
\gamma_{Z} \leq 1.1
$$

The condition above being satisfied, the structural calculation with fixed nodes can be performed on each compressed element alone. 
The element will be with the end linked to the other structural elements. According to NBR 6118: 2014, in section 15.6 - "nodes fixed structure Analysis", under the action of horizontal forces the structure is always calculated as displaceable.

The fact that the structure can be treated as fixed allows to disregard only the verification of the second order global effects. Local second-order effects must be considered.

The code NBR 6118 says that the global analysis of second order provides only internal forces at the ends of the bars and should be performed an analysis of the local second order effects along the axes of the compressed bars.

On the other hand, when the value of $\gamma_{Z}$ obtained from a first order analysis is higher than $\gamma_{Z}>1.1$, the structure should be considered of mobile nodes. In this case, the effects of physical and geometric nonlinearity should be necessarily be considered. It is therefore necessary to check the local and global second order effects.

When the value of $\gamma_{Z}$ is in the range of $1.1<\gamma_{Z} \leq 1.3$, NBR 6118:
2014 says that the global second order internal forces can be considered in an approximate way by adopting different values of stiffness for structural elements, which should be the same as shown in item 3.1.1. Finally, the final solution to the approximate consideration of the global second order internal forces is to increase the horizontal forces from the combination of load seen by $0.95 \gamma_{\mathrm{Z}}$, obtained after analysis of the first order structure. This process only applies to $\gamma_{Z} \leq 1.3$.

In other cases in which $\gamma_{Z}>1.3$ the structure will be of mobile nodes and must be verified the analysis of second-order effects considering refined methods such as $P-\Delta$.

\section{Structural modeling}

To apply the concepts of structural stability, this article will simulate of a building in a structural modeling software. The CAD/TQS software is one of the tools available in the Brazilian market to professionals involved in the preparation of structural design of re-

Figure 3 - Floor plan without wall-like columns

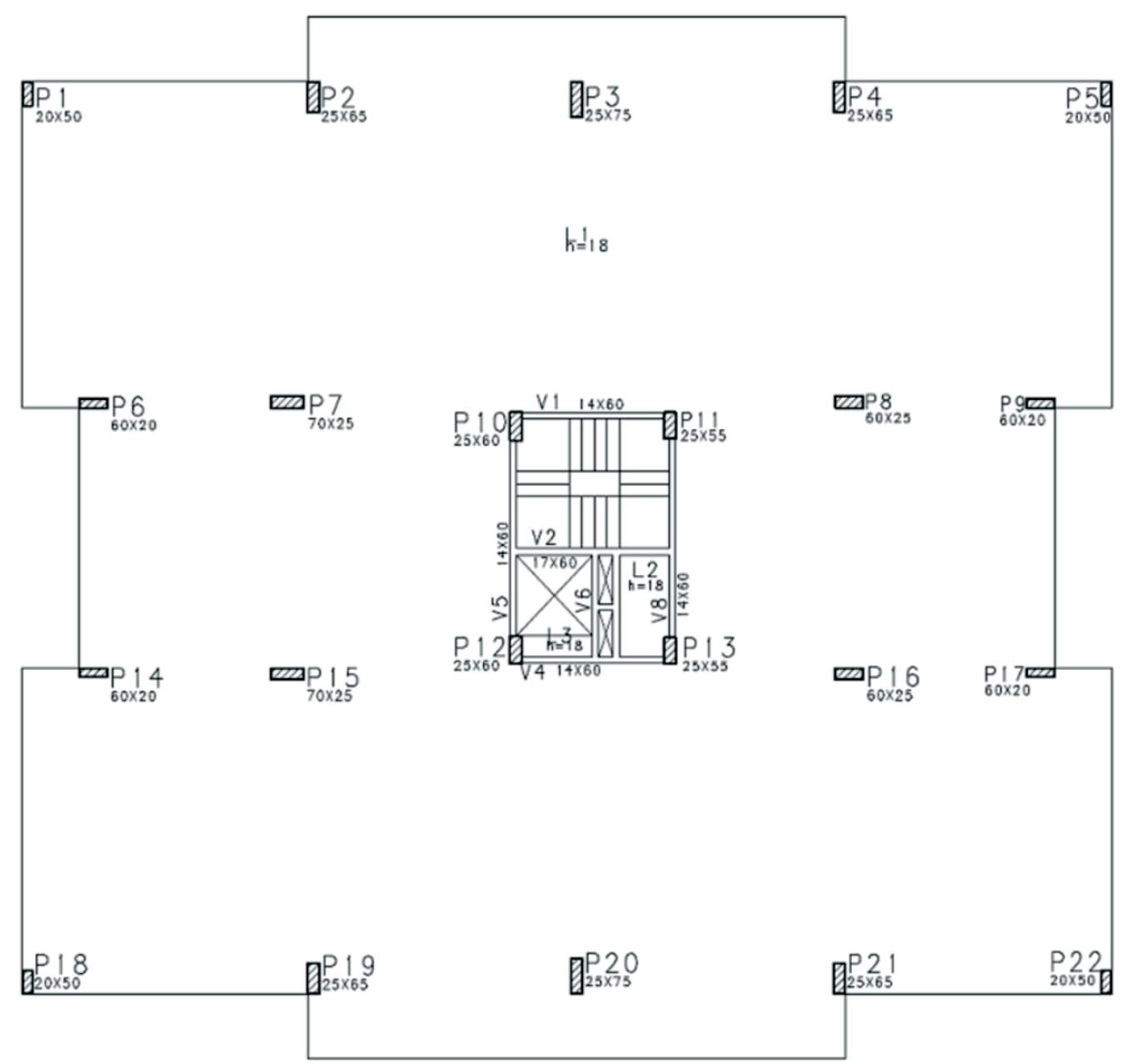




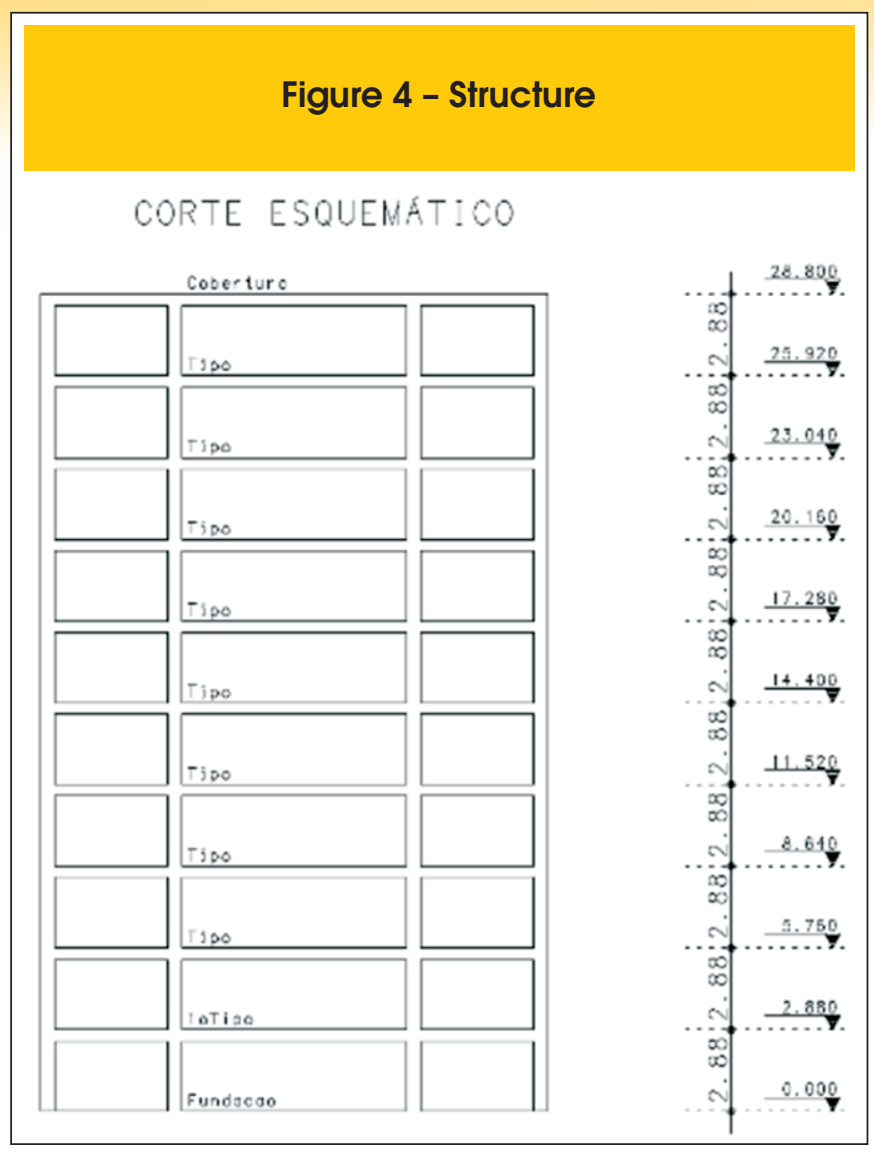

inforced concrete buildings and one of the most widely used.

Next will be presented the floor plan of the building used for simulation, variations of each model used, the description of vertical and horizontal loads to which the building is subject, the conditions and considerations adopted for structural analysis and presentation of values of $\alpha$ and $\gamma_{Z}$

\subsection{Structural model adopted}

The building consists of 10 floors (Figure 4) in accordance with the floor plan shown in Figures 3 and 5. Were adopted two structural solutions: one without wall-like columns (figure 3 ) and the other with wall-like columns (Figure 5). This condition was set to com-

\begin{tabular}{|c} 
Table 4 - Loads used on \\
the structural model
\end{tabular}

pare which are the effects when using wall-like columns.

The CAD / TQS version 17.8 software provides six models for design and structural analysis. In the case of this article "Model Vl", also known as Flexibility Model with Slabs, was adopted. This model is the most appropriate when is used to structural analysis of reinforced concrete buildings, because the model considers a three-dimensional space frame consisting of beams, columns and slabs. The model consists of bars, which simulate the slabs, beams and columns.

Table 6 - Preliminary design of Column P1 - Variation V1

\begin{tabular}{|cccccccccc|}
\hline Floor & Number & A.l. & C/Pav. & C. Pav. & C. Acum. & b & h & P.P. & Stress \\
\hline 1Oth Floor & 10 & 11,1 & 7 & 77 & 79 & 20 & 50 & 7 & 0,0794 \\
\hline 9th Floor & 9 & 11,1 & 10 & 111 & 198 & 20 & 50 & 7 & 0,1976 \\
\hline 8th Floor & 8 & 11,1 & 10 & 111 & 316 & 20 & 50 & 7 & 0,3158 \\
\hline 7th Floor & 7 & 11,1 & 10 & 111 & 434 & 20 & 50 & 7 & 0,4340 \\
\hline 6th Floor & 6 & 11,1 & 10 & 111 & 552 & 20 & 50 & 7 & 0,5522 \\
\hline 5th Floor & 5 & 11,1 & 10 & 111 & 670 & 20 & 50 & 7 & 0,6704 \\
\hline 4th Floor & 4 & 11,1 & 10 & 111 & 789 & 20 & 50 & 7 & 0,7886 \\
\hline 3th Floor & 3 & 11,1 & 10 & 111 & 907 & 20 & 50 & 7 & 0,9068 \\
\hline 2nd Floor & 2 & 11,1 & 10 & 111 & 1025 & 20 & 50 & 7 & 1,0250 \\
\hline 1st Floor & 1 & 11,1 & 10 & 111 & 1143 & 20 & 50 & 7 & 1,1432 \\
\hline Fundação & 0 & - & 0,0 & 0,0 & 1143 & 20 & 50 & 0 & 1,1432 \\
\hline
\end{tabular}


The structure was modeled considering the following horizontal loads provided in the code: plumb and wind; they were considered automatically by the software during the structural analysis. The wind speed was considered to $30 \mathrm{~m} / \mathrm{s}$, factor S1, S2 and S3 are respectively 1 , category IV-B and 1 .

The vertical loads considered in the floors below according to Table 4. In order to simplify the study and facilitate the comparison of results between each model, we chose to use surface charges for the masonry load.

\subsection{Pre-dimensioning of the columns}

The principal objective of this article is to vary the compression stress on the columns in order to relate these values with the stability parameters. For this, the pre-sizing of the columns was determined by the method of the areas of influence on each floor of the building. In accordance with what was previously presented by Table 4, the total load surface is $10 \mathrm{kN} / \mathrm{m}^{2}$.

The area of influence of each pavement was determined by the structural calculation software, but could be obtained manually considering that the distribution of loads occurs simply, i.e., a span between two columns in a defined direction, the influence of loads in each of these columns, is given until the middle of this span. Reworking this step for the other directions will be obtained an area. This area is equivalent to the distributed load that this column absorbs.

The characteristic strength of compression adopted for design was:

$$
f_{c k}=35 M P a
$$

The variation of compression stress in the columns is related according with the criteria that the reference value for design would be:

$$
\frac{2}{3} \times f_{c k}=\frac{2}{3} \times 35 M P a=23.3 M P a
$$

The models studied followed stress variations according to Table 5 . As an example, Table 6 presents how is determined the preliminary design of column $\mathrm{P} 1$, without wall-like columns, following $\mathrm{V} 1$ variation:

where:

Pav is the floor considered;

A.I. is the Influence Area in $\mathrm{m}^{2}$;

Figure 5 - Floor plan with wall-like columns

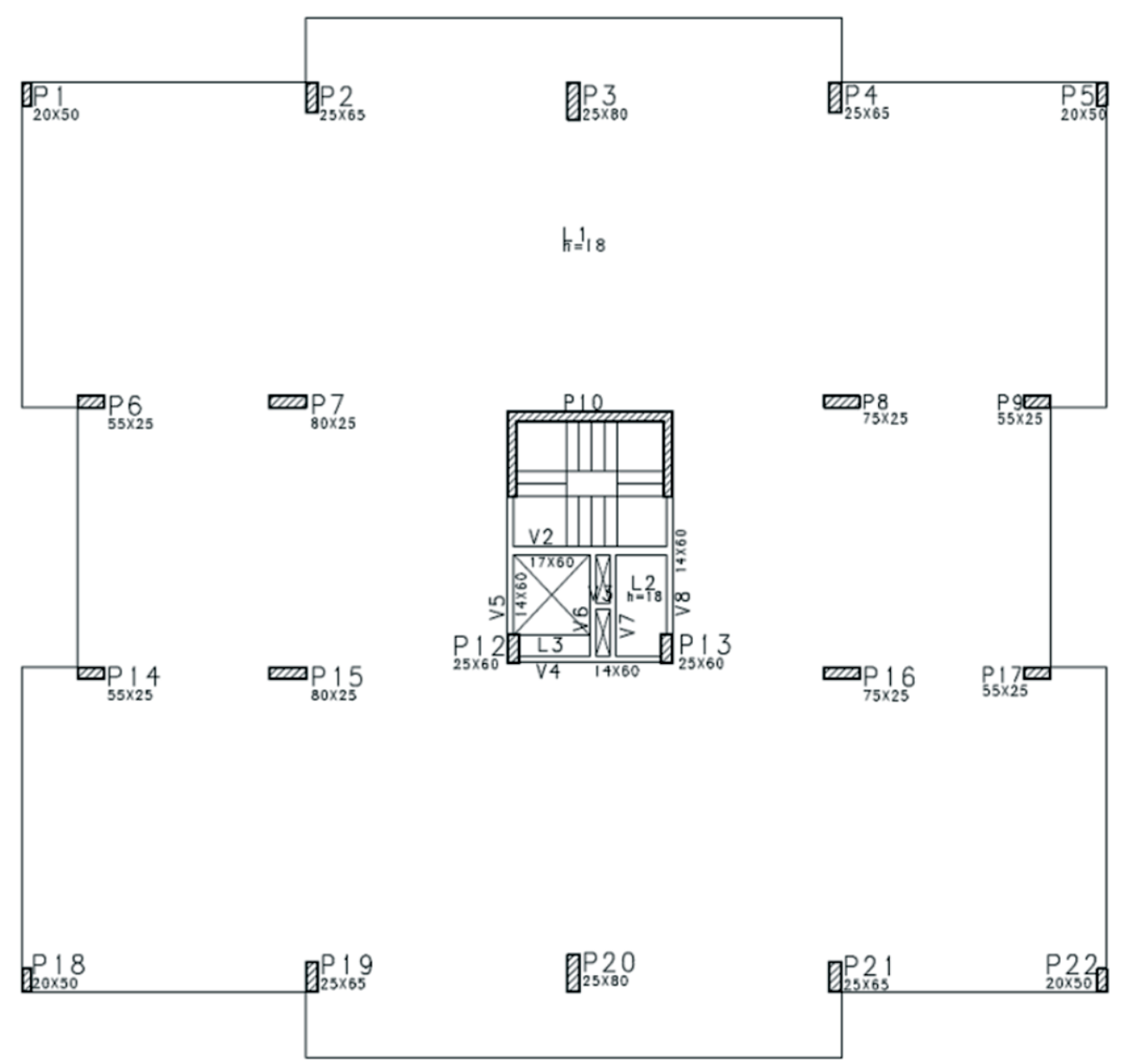


$\mathrm{C} / \mathrm{Pav}$ is the Full charge adopted on the pavement (given in Table 4), units in $\mathrm{kN} / \mathrm{m}^{2}$;

C. Pav is the Load obtained in the pavement for the column P1 $($ C.Pav $=C /$ Pav $\times$ A.I. $)$, units in kN; C. Acum: Load accumulated on the floor, where: C.Acum $=C . P a v+P . P .+C . A c u m$ pav,superior ;

$\mathrm{b}$ and $\mathrm{h}$ are the column section dimensions of the considered floor, in $\mathrm{cm}$;

P.P. is the Weight of the column, obtained by multiplying the crosssectional area of the column by floor height $(2,88 \mathrm{~m})$ and the dead weight of the concrete $\left(25 \mathrm{kN} / \mathrm{m}^{3}\right)$;

Column Stress for each floor is a value obtained by C.Pav $/ b \times h$, units in $\mathrm{kN} / \mathrm{m}^{2}$;

It is observed that the stress in the foundation and first floor do not exceed the limit value for the $\mathrm{V} 1$ range: $11.6 \mathrm{MPa}=1.16 \mathrm{kN} / \mathrm{m}^{2}$.

To simplify the presentation of the results, were developed the following models with the variations V1 to V5 (Table 5), where the dimensions of the columns were pre-determined by each floor plan with and without wall-like columns. Ten different models were determined in accordance with Table 7.

To obtain the results, the load combinations were considered in models presented in Table 8.

The dead and love loads were increased by $\gamma_{f}=1.4$ and wind loads with coefficient $\psi_{0}=0,6$. These values were obtained from the Brazilian code NBR 6120: 1980 - Loads for Building Structures Design.

\section{Results}

The proposed models were processed in the CAD/TQS software, through three-dimensional frame analysis, and the values obtained of $\alpha$ e $\gamma_{Z}$ are presented on table 9 .

\section{Conclusion}

After the presentation of the results using Table 9 and Graph 1, it can be seen that the values of $\gamma_{Z}$ obtained for the models calculated without wall-like columns are higher compared to models with wall-like columns, which was expected because the presence of the wall-like columns increases the bending stiffness of the building.

It is also observed that the variation of stress on the columns of the models with wall-like columns results in small differences of the coefficient $\gamma_{Z}$, with values between 1.064 and 1.161. On models without wall-like columns, the variation of the column stress modify significantly the values of $\gamma_{Z}$, making them between 1.197 and 1.426. It is possible to conclude, therefore, that the variation of the column stress is not the determining factor in acceptable $\gamma_{Z}$ values, but the presence of elements that contribute to increase stiffness bending. In this case, the author has chosen to use walllike columns, but alternatives can also be used, like beams with high stiffness, walls of reinforced concrete, increase of the columns sections in the direction of less rigidity of the structure.

In this article, the models with wall-like columns have $\gamma_{Z}$ values below the limit, being possible to disregard the second order analysis of the structure. It is only needed to perform first-order analysis and increase the internal forces according to the code recommendations. In models without wall-like columns, all of them with stress over $70 \%$ of the reference value, second-order analysis is needed.

\section{Table 7 - Types of models}

\begin{tabular}{|cc|}
\hline Description of the models & Name used for the model \\
\hline Model without wall-like columns and V1 & $1-1$ \\
\hline Model without wall-like columns and V2 & $1-2$ \\
\hline Model without wall-like columns and V3 & $1-3$ \\
\hline Model without wall-like columns and V4 & $1-4$ \\
\hline Model without wall-like columns and V5 & $1-5$ \\
\hline Model with wall-like columns and V1 & $2-1$ \\
\hline Model with wall-like columns and V2 & $2-2$ \\
\hline Model with wall-like columns and V3 & $2-3$ \\
\hline Model with wall-like columns and V4 & $2-4$ \\
\hline Model with wall-like columns and V5 & $2-5$ \\
\hline
\end{tabular}

\section{Table 8 - Used combinations}

\begin{tabular}{|cccccccc} 
Combination & Weight slab & Dead load & Live load & Wind $90^{\circ}$ & Wind $270^{\circ}$ & Wind $0^{\circ}$ & Wind $180^{\circ}$ \\
C1 & $X$ & $X$ & $X$ & $x$ & - & - \\
C2 & $X$ & $X$ & $X$ & - & $x$ & - \\
C3 & $X$ & $X$ & $X$ & - & - & $x$ \\
C4 & $X$ & $X$ & $X$ & - & - & - \\
\hline
\end{tabular}




\section{Table 9 - Results}

\begin{tabular}{|c|c|c|c|c|c|c|c|c|}
\hline \multirow{2}{*}{ Model } & \multicolumn{4}{|c|}{$\alpha$} & \multicolumn{4}{|c|}{$\gamma_{z}$} \\
\hline & $\mathrm{Cl}$ & $\mathrm{C} 2$ & C3 & $\mathrm{C} 4$ & $\mathrm{Cl}$ & $\mathrm{C} 2$ & C3 & $\mathrm{C} 4$ \\
\hline $1-1$ & 0.944 & 0.944 & 0.962 & 0.962 & 1.197 & 1.197 & 1.220 & 1.220 \\
\hline $1-2$ & 0.877 & 0.877 & 0.986 & 0.986 & 1.196 & 1.196 & 1.255 & 1.255 \\
\hline $1-3$ & 1.064 & 1.064 & 1.071 & 1.071 & 1.353 & 1.353 & 1.324 & 1.324 \\
\hline $1-4$ & 1.094 & 1.094 & 1.145 & 1.145 & 1.390 & 1.390 & 1.391 & 1.391 \\
\hline $1-5$ & 1.117 & 1.117 & 1.174 & 1.174 & 1.416 & 1.416 & 1.426 & 1.426 \\
\hline $2-1$ & 0.714 & 0.714 & 0.562 & 0.562 & 1.114 & 1.114 & 1.064 & 1.064 \\
\hline $2-2$ & 0.756 & 0.756 & 0.582 & 0.582 & 1.130 & 1.130 & 1.069 & 1.069 \\
\hline $2-3$ & 0.776 & 0.776 & 0.597 & 0.597 & 1.138 & 1.138 & 1.074 & 1.074 \\
\hline $2-4$ & 0.818 & 0.818 & 0.609 & 0.609 & 1.157 & 1.157 & 1.078 & 1.078 \\
\hline $2-5$ & 0.826 & 0.826 & 0.615 & 0.615 & 1.161 & 1.161 & 1.080 & 1.080 \\
\hline
\end{tabular}

In interpreting the values of $\alpha$ it is observed that most of the models set up with mobile nodes.

Thereby, this article presented the basic concepts of stability parameters $\alpha$ and $\gamma_{Z}$; presented the results of models simulations on the structural software CAD/TQS varying the compressive stress in the columns for the purpose of relating these values with the stability parameters $\alpha$ and $\gamma_{Z}$ and presented actions that could be taken in buildings to minimize the effects of global instability.

\section{References}

[1] ASSOCIAÇÃO BRASILEIRA DE NORMAS TÉCNICAS (2014). Projeto de estruturas de concreto - Procedimento, NBR 6118, Rio de Janeiro, RJ.
[2] ASSOCIAÇÃO BRASILEIRA DE NORMAS TÉCNICAS (1980). Cargas para cálculo de estruturas de edificações, NBR 6120, Rio de Janeiro, RJ.

[3] MONCAYO, W. J. Z (2011). Análise de Segunda Ordem Global em Edifícios com Estrutura de Concreto Armado. Master's degree dissertation, USP. São Carlos, 2011.

[4] VASCONCELOS, A. C. (1997). Origem dos Parâmetros de Estabilidade a e yz - Coletânea de Trabalhos sobre Estabilidade Global e Local das Estruturas de Edifícios. São Paulo, 1997.

[5] VASCONCELOS, A. C. e FRANCO, M. (1997) - Avaliação Prática dos Efeitos de 2a Ordem em Edifícios Altos - Coletânea de Trabalhos sobre Estabilidade Global e Local das Estruturas de Edifícios. São Paulo, 1997.

\section{Graph 1 - Comparison of obtained results}

\section{Comparação dos Valores obtidos de Gama-Z}

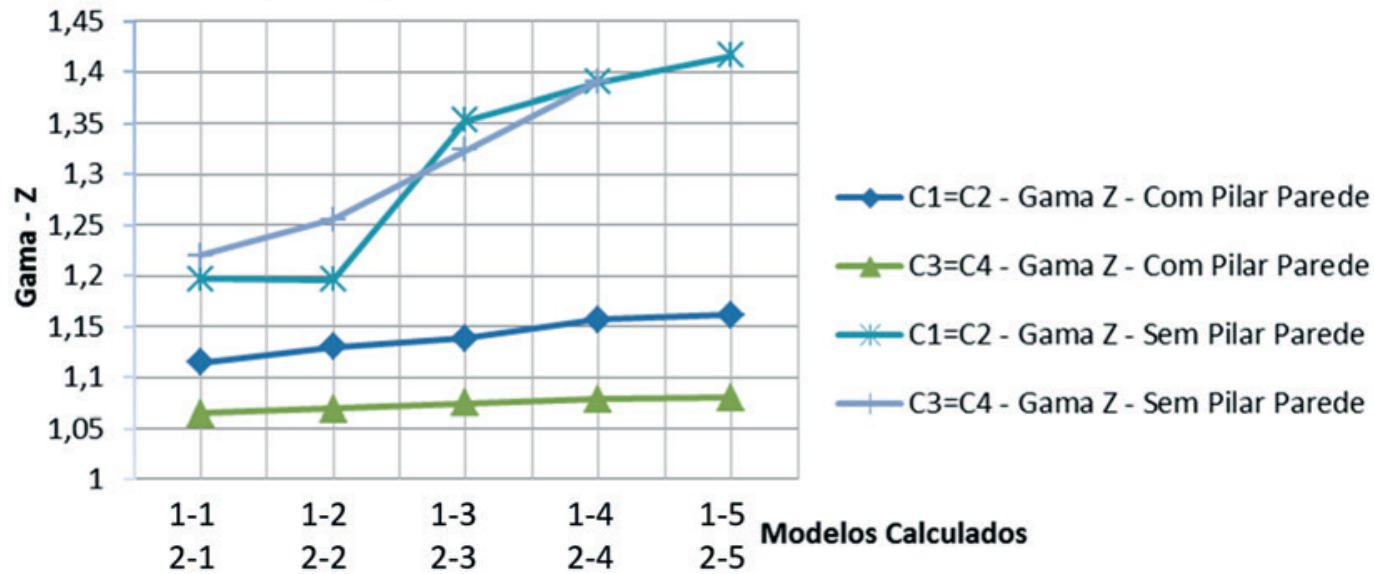


[6] VASCONCELOS, A. C. e FRANÇA, R. C. (1997) - Um método Simplificado e Muito Preciso para Avaliação dos Momentos de 2a Ordem em Edifícios Altos Usuais - Coletânea de Trabalhos sobre Estabilidade Global e Local das Estruturas de Edifícios. São Paulo, 1997.

[7] CARMO, R.M.S (1995) - Efeitos de Segunda Ordem em Edifícios Usuais de Concreto Armado - Master's degree dissertation. College of Engineering of São Carlos, University of São Paulo. São Carlos - SP, 1995. 